\title{
VOID POROSITY MEASUREMENTS IN COASTAL STRUCTURES
}

\author{
Carlos Bosma ${ }^{1}$, Henk Jan Verhagen ${ }^{2}$, Kees d'Angremond ${ }^{3}$, and Wouter Sint Nicolaas ${ }^{4}$
}

\begin{abstract}
The paper describes the use of two fundamental design parameters, the void porosity and layer thickness in rock armour constructions. These design parameters are very sensible for factors such as the boundary definition of a rock layer, rock production properties, intrinsic properties and construction properties. Differences in the value of the design parameter cause a considerable (financial) risk. This risk contains two directions, the first is the affection on the hydraulic performance of the structure and the second is its relation with materials procurement. This paper describes and investigates the second risk for the contractor: the large margin in the calculation of the void porosity, which influences the amount of rock (in weight). Often this risk is on account of the contractor, so it is necessary to have better insight in these values in order to reduce the financial risk. Focus is on the variation of the porosity at the bottom, at the top and at the transition between two layers of graded material. This has resulted in correction coefficients for the layer thickness, as well as for the computation of the void porosity as a basis for payment by the client.
\end{abstract}

\section{Notation}

$\rho_{\mathrm{r}}:$ density of rock (including rock voids) $\left[\mathrm{kg} / \mathrm{m}^{3}\right]$

$\rho_{\mathrm{b}}$ : bulk density $\left[\mathrm{kg} / \mathrm{m}^{3}\right]$

$\mathrm{D}_{\mathrm{n} 50}$ : nominal stone diameter $[\mathrm{m}]$

$\mathrm{t}$ : perpendicular thickness rock layer [m]

$\mathrm{n}$ : number of layers form which the rock layer is built [-]

$\mathrm{k}_{\mathrm{t}}$ : layer thickness coefficient [-]

1 Graduate student, M. Sc.-thesis for Delft University of Technology, Faculty of Civil Engineering, Section of Hydraulic Engineering. Currently: M. Sc. Civil Engineer, working for Van Oord ACZ (www.voacz.com), Specialized Dredging, Offshore and Marine Contractors P.O. BOX 458, 4200 AL Gorinchem, The Netherlands. cbosma@voacz.com.

2 Associate professor, Delft University of Technology, Section of Hydraulic Engineering, P.O.Box 5048, NL2600 GA Delft, The Netherlands, H.J.Verhagen@ct.tudelft.nl.

3 Professor, Delft University of Technology, Section of Hydraulic Engineering P.O. Box 5048, NL2600 GA Delft, The Netherlands.

4 M. Sc. Engineer, Van Oord ACZ, Specialized Dredging, Offshore and Marine Contractors P.O. Box 458, 4200 AL Gorinchem, The Netherlands.wsintnicolaas@voacz.com. 
$\mathrm{M}_{\mathrm{y}}$ : mass of an imaginary rock peace for which $\mathrm{y} \%(\mathrm{~m} / \mathrm{m})$ of the material consists of rock peace's lighter than this rock peace $[\mathrm{kg}]$

$\mathrm{F}_{\mathrm{s}}$ : $\quad$ shape factor rock, equal to 0.6 for rock and 1.0 for cubes [-]

$\mathrm{D}_{\mathrm{y}}{ }^{3}$ : sieve opening through which $\mathrm{y} \%(\mathrm{~m} / \mathrm{m})$ can pass $[\mathrm{m}]$

\section{INTRODUCTION}

The present paper presents some of the results of a study of the as placed characteristics of graded rock used in the construction of a rock armour construction. Rock armour is one of the most common construction materials to be in the front line of wave action on coast protection structures owing largely to its massiveness, durability, flexibility and low cost. However, its innate irregularity in geometry poses engineering problems by introducing variability and uncertainty into the final structure. This paper examines void porosity, as this important property is highly dependent on the natural irregularity of rock armour sizes and shapes.

There are two main reasons why packing density and the associated void porosity are important to coastal engineers. The first is that it affects hydraulic performance, because of energy dissipation occurring in the voids, which in turn affects wave reflections, stability, run-up and overtopping. The second is its relation with materials procurement. At the design stage, an understanding of packing relations is needed for estimating armour layer thicknesses and for dimensioning the cross-sections design drawings to be used by the contractor. Furthermore, the total tonnages of rock that must be ordered to make up the bulk volumes indicated on the drawings depend on the void space and thus the packing density. Uncertainty about voids and packing in the built structure lead to greater risk for both designer and contractor. The most direct financial risks are those associated with materials procurement and payment issues, while potentially more important but indirect financial risks relate to uncertainty in hydraulic performance. The paper does not consider the hydraulic implications of the variations in packing density and voids but will discuss the void space within armour layers and their layer thicknesses.

\section{Important Design Parameters}

Void porosity is one of the important parameters, which are responsible for computation of rock quantities in rock armour constructions. Porosity is influenced by several factors such as bulk characteristics (shape of grading and rock shape), construction characteristics (boundary definitions, surveying methods, placement techniques and influences of underlying layers) and intrinsic characteristics (color, shape, dimension, rock density water absorption strength and weathering). For narrow gradings $\left(\mathrm{D}_{85} / \mathrm{D}_{15}<1.5\right)$, simple relations for the as-built geometric properties of an armour layer have been cited widely. A good approximation for the void porosity $n_{\mathrm{v}}$ is given by e.g. CIRIA/CUR [1990] ${ }^{1}$.

$$
n_{v}=1-\left(\rho_{b} / \rho_{r}\right) \bullet 100 \%
$$

The void porosity, as defined in formula 1, defines the average porosity over the measured rock armour layer.

Layer thickness is next to the void porosity an important design parameter for rock armour structures. The layer thickness, mostly defined as the perpendicular layer thickness, is a frequently used design tool for dimensioning the cross-section drawings in the 
estimating phase. The layer thickness design tool is responsible for the computation of the volume of a certain rock armour layer. The CIRA/CUR [1990] $]^{2}$ gives the following definition for the perpendicular layer thickness:

$t=n \bullet k_{t} \bullet D_{n 50}$

The size of the layer thickness depends on the value of the layer thickness coefficient. This coefficient is a correction for the fact that the thickness of a double rock layer will not be equal to two times the nominal rock diameter. The layer thickness coefficient is determined by field tests, which are executed on a large number of rock constructions. Both design parameters are very sensible for the definition of the boundary of de rock layer. A difference in de boundary definition will directly influence the layer thickness and void porosity. The sensibility of the design parameters for boundary definition makes it necessary to define two different definitions for the porosity.

\section{Real void porosity}

Actual value for the void porosity in a rock structure. The boundary definition and the applied surveying methods do not influence this value and represents the void porosity in an infinitive rock structure without any boundaries.

\section{Imaginary void porosity}

Measured value for the void porosity in which the volume of the built rock structure is determined with a certain surveying method. The surveying method is responsible for the measured boundary and thus the definition of the boundary for the rock structure. The imaginary void porosity is an average value measured over this certain rock layer.

The imaginary void porosity is the definition of the porosity after the rock construction is built and measured. The real void porosity is the definition of the porosity that is used in the calculation- and tender phase. The difference between the two definitions is the main reason for the difference in calculated and real void porosity values. The uncertainty about the void porosity is clarified by comparison of three existing standard guidance's for typical as-built properties of randomly placed irregular and rounded armour in table 1.

Table 1. Existing guidance for typical as-built properties of randomly placed irregular and rounded armour

\begin{tabular}{|c|c|c|c|}
\hline Shape of rock & $\begin{array}{l}\text { SPM }(1984)^{2} \\
\text { BS } 6349(1991)^{3}\end{array}$ & QMW/HR (1988) & CIRIA/CUR (1991) \\
\hline $\begin{array}{l}\text { Equant and irregular } \\
\mathrm{k}_{\mathrm{t}} \\
\mathrm{n}_{\mathrm{v}} \text { : \% } \\
\text { Rounded }\end{array}$ & $\begin{array}{c}1.15 \text { (rough) } \\
40\end{array}$ & $\begin{array}{c}0.75-0.85 \\
37-39\end{array}$ & $\begin{array}{c}0.75-1.20 \\
38-40\end{array}$ \\
\hline $\begin{array}{l}\mathrm{k}_{\mathrm{t}} \\
\mathrm{n}_{\mathrm{v}}: \%\end{array}$ & $\begin{array}{c}1.02 \text { (smooth) } \\
38\end{array}$ & $\begin{array}{c}0.73 \\
35\end{array}$ & $\begin{array}{c}0.8-1.2 \\
35-37\end{array}$ \\
\hline
\end{tabular}

The CIRIA/CUR ${ }^{1}$ rock manual draws attention to the limitation and suggests that a wide range of layer thickness coefficients, and hence of void porosity's, may be applicable, 
depending on a range of material and constructional factors. In particular, the designer may have used a layer thickness coefficient $k_{t}$ in the SPM recommended range of 1.021.15 for double armour layers, when other recent studies by Queen Mary and Westfield College and Hydraulics Research indicate that a value of between 0.75 and 0.9 may have been more appropriate. As a result, the contractor may find it difficult or impossible to build the structure to the design tolerances with the particular armour rock type and constructional methods agreed at the outset of the contract. The existing guidance for these as-built parameters from different authorities is difficult to compare directly, but has been summarized in Table 1 for irregular and rounded armour blocks.

\section{Main Influences on Porosity Calculation}

The main influences responsible for determining the void porosity have been presented in the above paragraphs. Their mutual relations can be expressed in a flowchart presented in figure 1 .

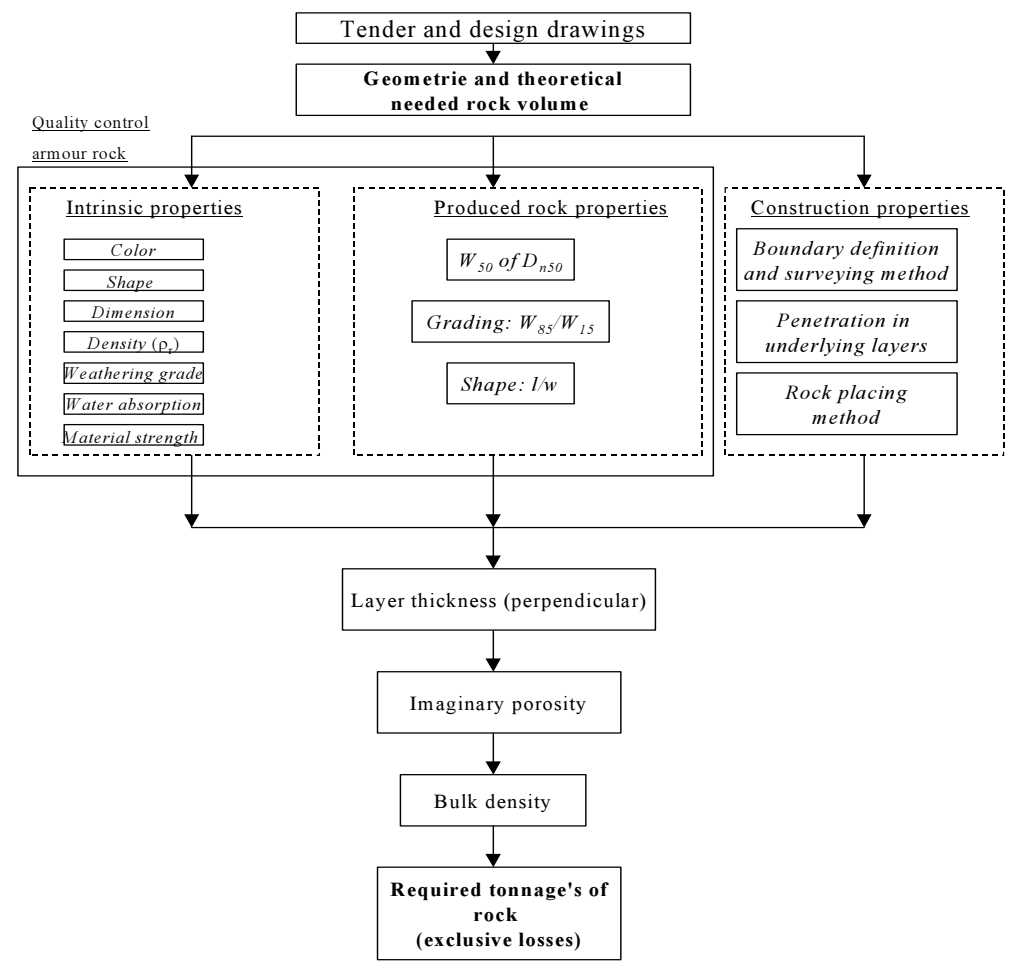

Figure 1. Influences on void porosity.

\section{Intrinsic Properties}

Intrinsic properties relate to the quality of the used armour rock. The intrinsic properties can be divided in color, shape, dimension, density, weathering, water absorption, and material strength. Shape and dimension are properties, which return in the production properties and will not be discussed in this paragraph. The other intrinsic properties can be monitored and checked according to quality systems in such a way that influences from this group can be neglected.

\section{Produced Rock Properties}

The rock production properties can be expressed in three different properties: 
nominal stone diameter $\left(\mathrm{D}_{\mathrm{n} 50}\right)$, shape of rock grading expressed as $\mathrm{W}_{85} / \mathrm{W}_{15}$ and shape expressed as $1 / \mathrm{w}$ (length/width). Bregman, M. $[1998]^{5}$ investigated the rock production properties for his M. Sc.-thesis for Delft University of Technology. As expected, the production properties have significant influence on void porosity value. Each of the three defined production properties can influence the void porosity, which results in a variation for the porosity value (according Bregman) from 3\% to 5\%.

\section{Construction Properties}

The construction properties can be divided in three different groups: method of placement, influence of underlying (rock) layers and the boundary definition and thus the surveying method. The fist group maintains a direct relationship with the porosity value in rock structures and thus influences the real porosity. The two remaining groups do not influence the real porosity, but directly influence the imaginary porosity value.

Knieß, H.G., [1977] ${ }^{6}$ describes the porosity values in the transition of a (hard and soft) filter layer into a rock layer. According to Knieß the transition area of a layer can be defined as $1 / 6$ part of the total layer height. A different average porosity value is defined for each transition (bottom or top transition of the rock layer). The average porosity value depends on the type of transition (e.g. transition between a soft under layer and a rock layer has a porosity of $0 \%$, transition between a hard under layer and a rock layer has a porosity of $60 \%$ ). Using porosity values for the transitions and an average porosity value (according to e.g. CIRIA/CUR ${ }^{1}$ ) for rest of the layer results in higher average porosity over the whole layer. The principle of Knieß his theory seems very logical, but the values and definitions used in his paper are not provided with any proof. Comparing with coastal structures is questionable because Knieß his paper refers to filter layers in road construction.

The boundary definition is important for determining the imaginary porosity, but the boundary itself is dependent on the used surveying method. Latham, J.P., and Gauss, G.A., $[1995]^{7}$ investigated the influence of different surveying methods on the bulk density and void porosity. In the past there has been no generally accepted surveying methods for determination of the armour layer surface profile. Three methods of defining and measuring the armour layer surface profile were used in order to assess the influence of the method of measurement on the results. The surface was defined by the base of a hemispherical probe of diameter $0.5 \mathrm{D}_{\mathrm{n} 50}$ using EDM equipment (recommended in the CIRIA/CUR Manual ${ }^{1}$ ). Using a conventional leveling staff and different intervals or high spots created differences in the surveying method. Variation in the surveying method resulted in substantially different layer thickness coefficients (ranging from 0.76 to 0.92 ). Measured void porosity's were generally significantly lower (ranging from $24 \%$ to $37 \%$ ) than those quoted in the standard armour texts. This investigation demonstrates the influence of the surveying method; still the link with the boundary definition (and also void porosity) is missing.

Investigations have been carried out to relate the void porosity $n_{v}$ to the layer thickness T. However, this assumes that the layer thickness can be measured. Unfortunately here is a large problem. Basically several ways exist to measure the layer thickness, e.g. measurements of the highest points, using hemispherical probe (with size of $.5 \mathrm{D}_{\mathrm{n} 50}$ ) or a conventional staff. In reality the porosity is not constant over the layer thickness. When a layer is placed on a hard bed the porosity of the layer will be $100 \%$ at 
the boundary, and decrease to a value of approx. $30 \%$. At the top of the layer, the porosity will increase again to $100 \%$. Defining a theoretical layer thickness $\mathrm{T}_{\mathrm{t}}$, which represents the porosity distribution as a block function instead of the real distribution function, will create a tool for the rock quantity calculation. Testing the differences between the average layer levels (measured by the surveying method) and the layer thickness $T_{t}$ creates a tool for classification of the different surveying methods. This is indicated in figure 2.

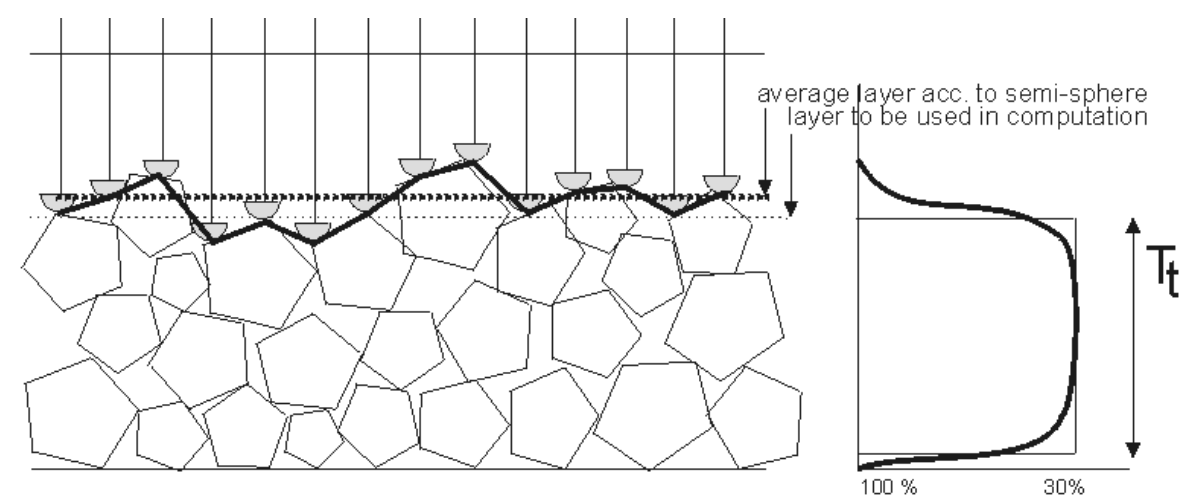

Figure 2. Measuring the top of a stone package

\section{Study Objectives}

In the above paragraphs the problem is extracted to different properties. The intrinsic properties can be monitored in such a way that the influence can be neglected for void porosity calculations. The rock production properties have been investigated by Bregman $[1998]^{6}$ and are not attractive for further investigation. This study will focus on the construction properties of rock armour structures. As there has in the past been no generally accepted surveying method for the determination of the rock layer surface profile, this study describes a comparison of the porosity distribution through a rock layer with the results of different surveying methods, including the method recommended in the CIRIA/CUR Manual ${ }^{1}$. The study objectives were, in summary, as follows:

(a) Porosity distribution over rock layers, through transitions of rock layers and transition with the environment (subsoil and atmosphere).

(b) Comparing surveying results with porosity distribution. Surveying methods as recommended in the CIRIA/CUR Manual ${ }^{1}$, executed with different intervals and using the conventional surveying staff.

(c) Penetration of rock layers in underlying layers (filter rock or subsoil).

(d) To provide future guidance on the above mentioned design parameters.

\section{STUDY METHODS}

\section{Schematization}

To achieve the objectives of this study it is necessary to make a schematization of the real situation. In this simplified environment it is possible to execute the necessary test to describe en test the above mentioned objectives. The simplified environment is built by using a so-called "model investigation". This model contains the right degrees of freedom 
to investigate the mentioned properties.

Using one rock source neglects the influence of the intrinsic properties and will not disturb the test results. Rock production properties do have a certain influence on the void porosity as stated by Bregman ${ }^{5}$. The shape of the grading expressed by $\mathrm{W}_{85} / \mathrm{W}_{15}$ must be constant for all the used gradings. The same demand must be stated for the shape of the rocks expressed by $1 / \mathrm{w}$ (length/width). Implementation of the above stated demands will have a direct influence on the compilation of the used rock gradings and will be used as the boundary definition for the compilation of all the gradings in the tests.

The model to be used for the tests must be equipped for two different ways of measuring. The first measuring method will be equal to the practical used surveying methods for measuring the surface of a rock structure. Differentiation in the surveying method has been achieved by using two different measuring staffs: the hemispherical probe (with size of $0.5 \mathrm{D}_{\mathrm{n} 50}$ ) and the conventional staff (measuring probe with a sharp end). Measuring intervals have been taken at $0.75 \mathrm{D}_{\mathrm{n} 50}$ in two directions ( $\mathrm{x}$ - and $\mathrm{y}$-direction, recommended in the CIRIA/CUR Manual ${ }^{1}$ ).

The second measuring method is necessary for measuring the porosity distribution over the rock layers. This will be measured by filling the 'test basin' with water in small steps with known volume. Each time after filling the water level rise will be measured, which indicates the porosity distribution. Each measurement determines the average porosity over the area of the test basis over a small height $\Delta \mathrm{h}$. The average porosity will include boundary effects, which appear near the edges and the bottom of the test basin. The porosity distribution will be corrected with known correction formulas for boundary effects to achieve the real distribution in the rock layers.

The literature assigns the method of placing as one of the factors that will influence the porosity in rock structures. Influence by the method of placement can be ignored if the effect on the porosity is constant during the tests. The best method for placing will be a random placement method, which excludes the influence of men the most. Dumping the rock in the test basin filled with water is the best way to achieve this random placement method. Above described schematizations have been used as boundaries for the schematization of the test basin.

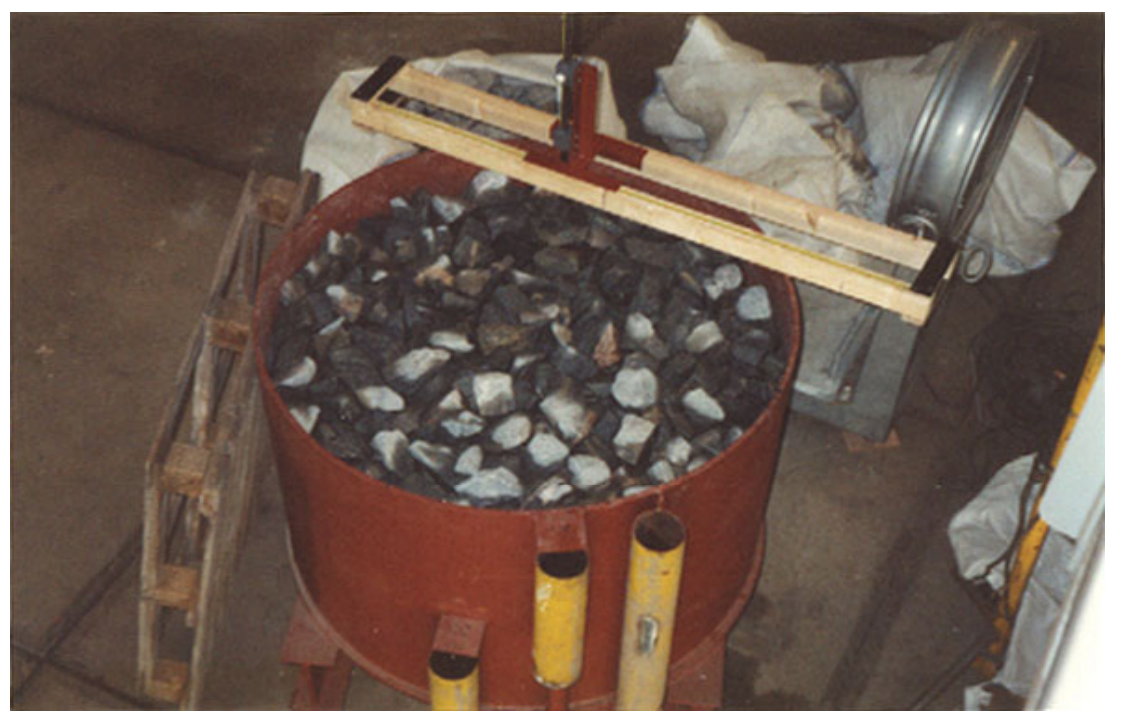

Figure 3. Photo test basin 


\section{Rock Gradings}

\section{Dimensions}

Dimensions of the used rock in the test have been determined by several factors that influence the minimum and maximum dimensions. The minimum dimension has been determined by capillary rising of the water level in the voids of the rock structure. The minimum rock dimension that gives no capillary rising of the water level has been tested. The test results stated that the minimum rock diameter $\mathrm{D}_{50}$ must be equal or bigger than 8.5 millimeter.

Maximum dimensions of the rock have been determined by two factors: the weight of the rock (rock handling executed by men, which gives an upper limit for rock weight) and the boundary effect corresponding with the maximum dimension. The relation between weight and dimension of rock is given by formula 3 .

$$
M_{y}=F_{s} \bullet \rho_{r} \bullet D_{y}^{3}
$$

A maximum rock weight of $20 \mathrm{~kg}$ corresponds with a maximum dimension $\mathrm{D}_{85}$ of 230 millimeter.

A maximum permissible correction factor for the boundary effect was set on 1.1. The relation between test basin dimensions and the correction factor shows that a maximum rock dimension $\mathrm{D}_{85}$ equal to 185 millimeter gives the best solution. Demands for the boundary effect seems to be normative for the maximum rock dimension. $\mathrm{D}_{85}=185$ millimeter will be used as the maximum rock dimension for the rock gradings in the tests.

\section{Shape}

Shape of a rock grading can be expressed by $D_{85} / D_{15}$ and is one of the factors influencing the porosity in rock structures. Using the same shape for all the test gradings will exclude the effect on porosity. Common practice shows a range of standard gradings, which are presented in the NEN-norms 5180 to $5186(1990)^{8}$. For standard light en -heavy gradings the shape factor $\mathrm{D}_{85} / \mathrm{D}_{15}$ varies between 1.9 and 1.15 . A typical shape for the standard gradings is equal to the standard grading $40-200 \mathrm{~kg}$. The shape factor $\mathrm{D}_{85} / \mathrm{D}_{15}$ for this grading is equal to 1.57 .

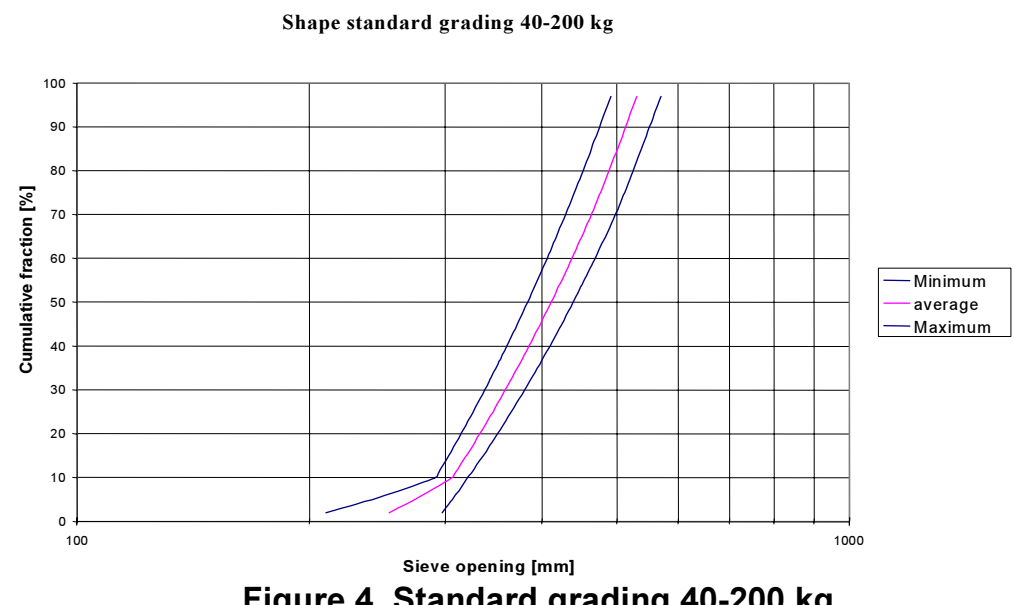

Figure 4. Standard grading 40-200 kg 


\section{RESULTS}

\section{Data Schematization}

During the test different measuring equipment has been used. Each measurement contains an error, which is known for all the used equipment. When a large number independent stochastically variables, from which no variable is dominating, are added regardless the starting distribution from those variables, a normal distribution is formed. This phenomenon is better knows as the central limit theorem. This theorem can be used for compiling al the gained data and also for implementation of errors, due to measurement, in the end result.

Each dataset accumulated by the individual measurements of the water level have been used to visualize the porosity distribution in rock layers. Hence the dataset consists a certain spreading, which makes it difficult to distinguish the porosity distribution. Therefore the datasets have been schematized by a normal distribution with an average value and the variation of this average. The execution of the schematization is expressed in figure 5 .

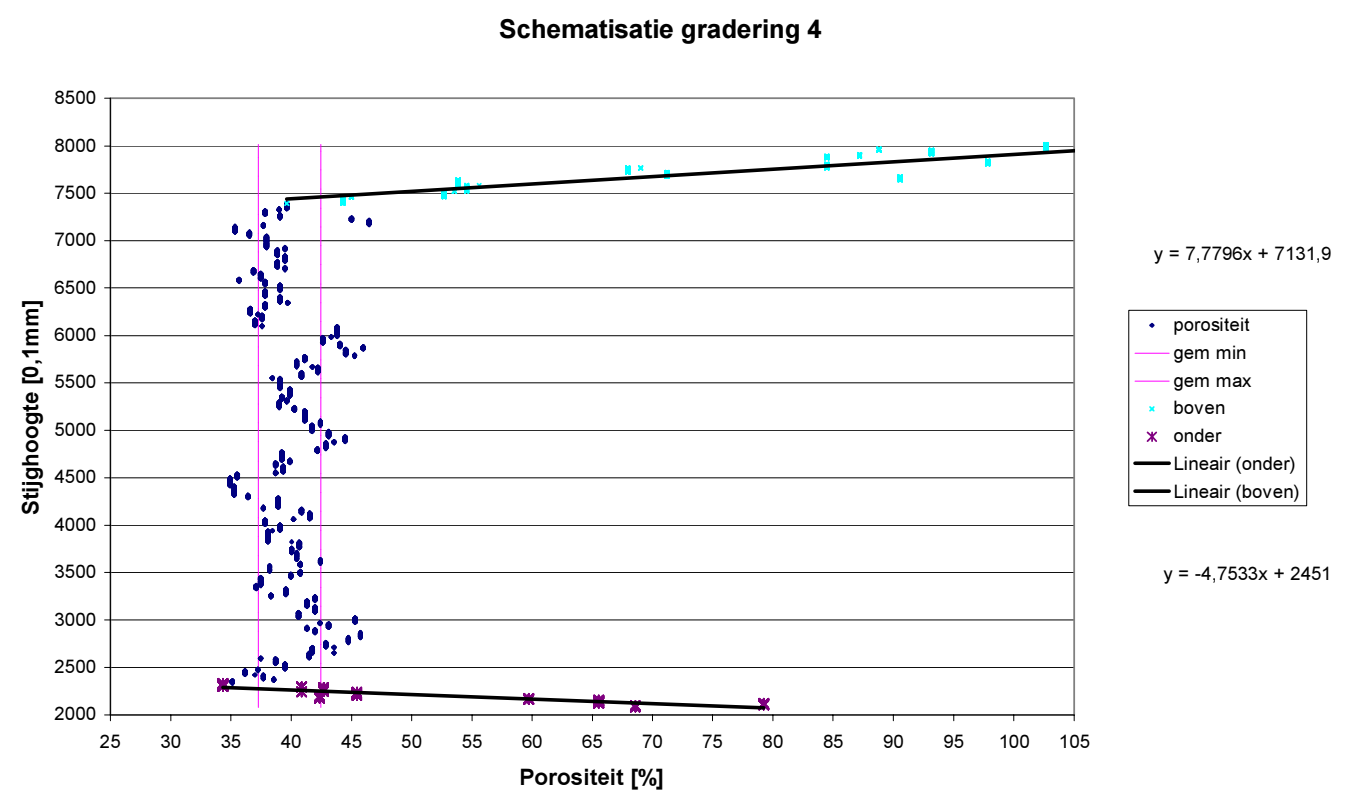

Figure 5. Schematization test data.

The dots in the figure represent individual measured points, which have been divided in three parts: the middle part represents the bulk porosity and the bottom- and top transitions, reproduced by linear regression lines. The center of these regression lines represents the level that can be defined as the theoretical boundary. When the bulk density is represented by its average the schematization is finished. The dataset can now be represented by a 'block function' in which the linear top- and bottom transitions have been replaced by the theoretical boundary. This boundary is the actual layer height over which the amount of rock can be calculated by multiplying this height with the bulk density. 


\section{Porosity Distribution}

To express the porosity distribution it is important to focus on the top- and bottom transitions. The height, over which the porosity increases from the bulk porosity to the maximum porosity of $100 \%$ in the boundary of the rock layer, is defined as the influence length.

\section{Single Rock Layer}

Data from the test have been used to calculate the influence length for the top and the bottom of a single rock layer, which is placed on a hard surface. The result of this calculation is a value for the influence length for top- and bottom transitions as a function of $\mathrm{D}_{\mathrm{n} 50}$ (table 2).

\begin{tabular}{lc}
\hline & Influence length $\left[{ }^{*} \mathrm{D}_{\mathrm{n} 50}\right]$ \\
\hline Bottom transition & $0,275 \pm 0,013$ \\
Top transition & $0,74 \pm 0,036$ \\
\hline
\end{tabular}

Table 2. Influence length single rock layer.

\section{Transition between Rock Layers}

The partition between the two rock layers is defined in the point where the maximum porosity appears. From the test data it appears that the maximum porosity can be expressed by $59,1 \% \pm 1,5 \%$. The influence lengths can be expressed as a function of $\mathrm{D}_{\mathrm{n} 50}$ from both rock layers. The functions describe the regression lines, which represents the data points in the transitions. The influence length for the top transition of the bottom layer can be expressed by formula 4 :

$$
I_{\text {top }}=0,5741\left[\frac{D_{n 50 \text { toplayer }}}{D_{n 50 \text { bottomlayer }}}\right]^{0,0153} \bullet D_{n 50 \text { bottomlayer }}
$$

The influence length for the bottom transition of the top layer can be expressed by formula 5:

$$
I_{\text {bottom }}=0,3452\left[\frac{D_{n 50 \text { toplayer }}}{D_{n 50 \text { bottomlayer }}}\right]^{0,1207} \bullet D_{n 50 \text { toplayer }}
$$

These influence lengths describe all the different transition zones. Surprising is that the influence length on a hard surface smaller is than the influence length by placing on a rock layer. A logical thought is that the rough surface of the rock layer should be filled with rock from the top layer, which should result in a small influence length. Hence the test results shows that this reasoning is not true. A simple explanation is that the rock on the hard surface will fall on their flat side and the holes between them will be filled with the rock above. This results in a rapid decrease of the porosity, which explains the test results.

\section{Surface Measurement}

Surface measurements have been carried out with a hemispherical probe and a pin 
shaped probe. Difference in methods is stated by the difference of the datasets from the two methods. The reliability is expressed by the spreading of the differences between the datasets. After treatment the difference between the two methods can be expressed as a function of $\mathrm{D}_{\mathrm{n} 50}$ and is given in formula 6 .

$y=0,204 D_{n 50}+0,18 \quad[m]$

As can be expected the measurement executed with the hemispherical probe gives a higher average surface level. This is a logical conclusion because the sphere will not measure the holes between the rocks, while the pin shaped probe takes all the holes in account.

Combining the surface measurements with the reference of the porosity distribution gives insight in the lying of the measured surface level. As reference the theoretical boundary or the top of the rocks can be used. The difference between the top of the rock (point where porosity reaches $100 \%$ ) and the measured surface can be expressed by formulas 7 en 8.

$$
\begin{aligned}
& y_{\text {hemispherical }}=0,462 D_{n 50}-0,04 \\
& y_{\text {pin shaped }}=0,667 D_{n 50}+0,08
\end{aligned}
$$

\section{Penetration in Underlying Layers}

The penetration is expressed by difference between two measured layer thicknesses, which have been placed on different subsoil's (rock or hard subsoil). The difference is measured and calculated for both used surveying methods. The penetration can be expressed as a function of the $\mathrm{D}_{\mathrm{n} 50}$ of both rock layers.

Measuring with the hemispherical probe shows a small penetration between 0 and 0,5 centimeter. The pin shaped probe gives much more spreading and a penetration between 1,0 and 2,5 centimeter. Because of the spreading, caused by the measuring method itself, the results is not reliable. Hence the penetration measured with the hemispherical probe is very small and can be neglected for an average rock layer.

\section{CONCLUSIONS AND RECOMENDATIONS}

The test results can be usefully in calculation with rock structures. Especially the transition zones can be handled in a different way. The best way to present the use of the given formulas is by schematizing a rock structure for calculation purposes. The schematization is given in figure 6 . The porosity distribution is schematized as parts with average porosity values. These values can be calculated out of the known influence lengths, bulk porosity's and used surveying method. The heights $\mathrm{F}$ and $\mathrm{T}$ in the figure can be calculated with formulas obtained from the tests:

- $\mathrm{F}_{1} 0,275 * \mathrm{D}_{\mathrm{n} 50 \text { filterlayer }}$

- $\mathrm{F}_{2} \mathrm{D}_{1}-\mathrm{F}_{1}-\mathrm{F}_{3}$

$\mathrm{F}_{3} \quad I_{\text {top }}=0,5741\left[\frac{D_{n 50 \text { toplayer }}}{D_{n 50 \text { bottomlayer }}}\right]^{0,0153} \bullet D_{n 50 \text { bottomlayer }}$ 
- $\mathrm{T}_{1} \quad I_{\text {bottom }}=0,3452\left[\frac{D_{n 50 \text { toplayer }}}{D_{n 50 \text { bottomlayer }}}\right]^{0,1207} \bullet D_{n 50 \text { toplayer }}$

- $\mathrm{T}_{2} \mathrm{D}_{2}-\mathrm{T}_{1}-\mathrm{T}_{3 \mathrm{a}}$

- $\mathrm{T}_{3} \quad 0,74 * \mathrm{D}_{\mathrm{n} 50 \text { top layer }}$

- $\mathrm{T}_{3 \mathrm{a}} \mathrm{T}_{3}-\mathrm{T}_{3 \mathrm{~b}}$

- $\mathrm{T}_{3 \mathrm{~b}} 0,462 * \mathrm{D}_{\mathrm{n} 50}-0,04$ (for surface measurement with hemispherical probe)
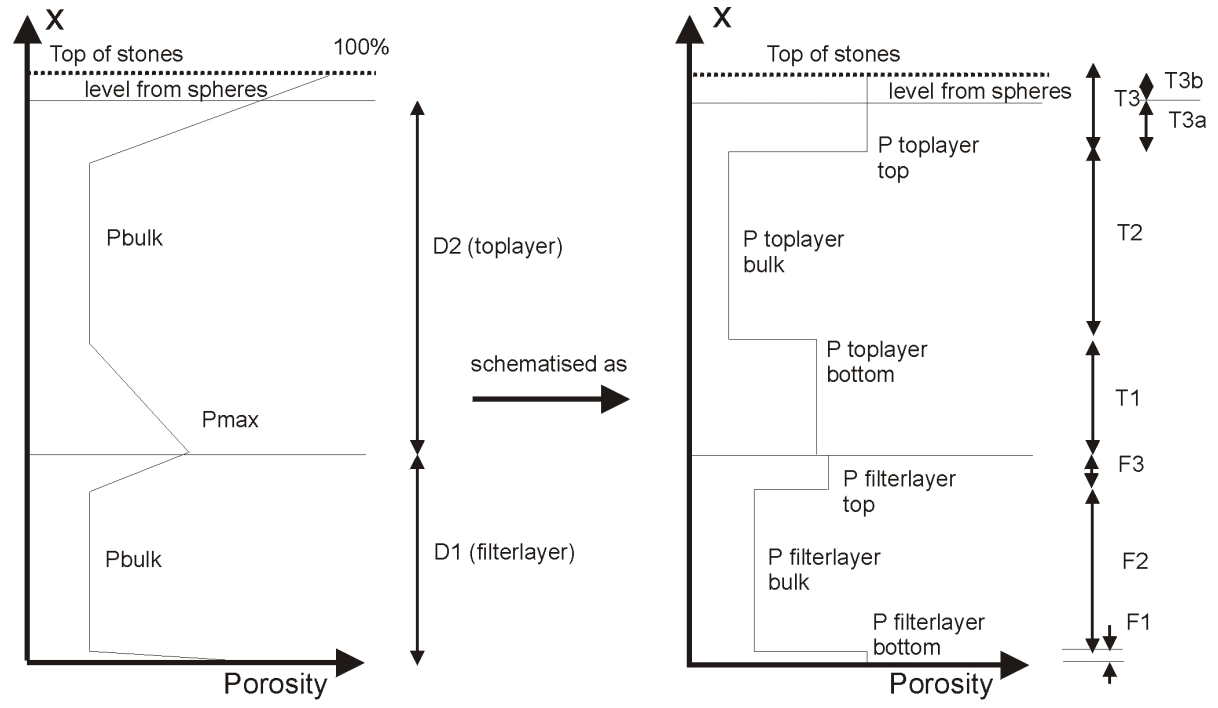

Figure 6. Schematization porosity distribution

The CIRIA/CUR Manual recommends an unequivocal surveying method for rock structures above the water surface. This recommendation must be implemented world wide because of the difference in two common used surveying methods. The difference can be expressed by formula 6 .

$y=0,204 D_{n 50}+0,18 \quad[m]$

The test represented the real value of the surveying method by comparing with the porosity distribution. This gives insight in what de used surveying method measured. The measured levels can e.g. be compared with the theoretical boundary or the top of the stones.

The porosity distribution given by Knie $\beta$ seems to be a good method. Hence Knie $\beta$ used always the same value for the influence length, which can now be expressed as a function of the rock diameter. The value found for the maximum porosity in transitions between rock layers is equal to the $60 \%$ Knie $\beta$ suggested.

Penetration of rock layers in underlying layers or subsoil has not been proved within these tests. The penetration found surveying with the hemispherical probe is small and can easily be neglected, while the pin shaped probe gives to much spreading for a reliable result.

It should be emphasized that the present study deals only with a certain type of rock structure, and care should be exercised in the extrapolation of the results to other 
structures. At first application of the results must be restricted and tested on horizontal constructions. However, it is considered that the methods and materials used were not untypical of those used in many similar structures because they have been selected on these criteria. Full scale tests, or comparing with as-built parameters must give more information about the reliability of the executed test.

Future studies of the kind described here would be extremely valuable for evaluation of the above conclusions. These may be extended with rock structures on a slope, implication of different placement methods and the use of different materials e.g. cubes used as 'armour rock'. Combining of the recent study's referring to void porosity will be extremely useful. Such a study can result in a method, which uses bulk properties, construction properties and intrinsic properties. As this practice becomes more widespread, and the documentation of results is pooled, it is possible to foresee an improvement in both the efficiency of the design of rock structures, and in designercontractor relations in this somewhat controversial area of quantity surveying.

\section{ACKNOWLEDGEMENTS}

BOSMA C.F. $[2001]^{9}$ bases this paper on his M. Sc.-thesis study for Delft University of Technology, faculty of Civil Engineering. Van Oord ACZ Marine Contractors, Specialized Dredging, Offshore and Marine Contractors, Gorinchem, Netherlands, supported this work, the test were conducted in the facilities of Van Oord ACZ in Zuilichem.

\section{REFERENCES}

${ }^{1}$ CIRIA/CUR [1990] Manual on the use of rock in coastal and shoreline engineering. CURReport 154 Balkema, Rotterdam (ISBN 905410 1024).

2 US Army Corps of Engineers. The shore protection manual (SPM). US Army Corps of Engineers, Coastal Engineering Research Centre, US Government Printing Office, Washington DC, 1984, 4 edn.

${ }^{3}$ British Standards Institution. Code of practice for maritime structures: Part 1, General criteria. BSI, London, 1984, BS 6349.

${ }^{4}$ Latham J.-P. et al. The influence of armourstone shape and rounding on the stability of armour layers. Coastal Engineering Research Group, Queen Mary and Westfield College, London, 1988, Report 1.

${ }^{5}$ Bregman, M., 1998, Porositeit in geplaatste steenlagen, onderzoek naar de factoren die de hoeveelheid geplaatst steenmateriaal beïnvloeden. M. Sc.-thesis for Delft University of Technology, Section of Hydraulic Engineering, Royal Boskalis Westminister N.V.

${ }^{6}$ Knieß, H.G., 1977. Bemessung von Schüttstein-Deckwerken im Verkehswasserbau; Teil 1: lose Steinschüttungen.

${ }^{7}$ Latham, J.P., and Gauss, G.A., 1995. The measurement of layer thickness and the estimation of as-built bulk density and void porosity in a rock armour revetment at Beesands, South Devon. Proc. of Instn. of Civ. Engs, Water Maritime and Energy. ISSN 0965-0946.

${ }^{8}$ Nederlandse Norm, NEN, September 1990. NEN 5180-5186 broken rock: terms, definitions, demands and tests.

${ }^{9}$ Bosma C.F. [2001] Porositeit in breuksteenconstructies. M. Sc.-thesis Delft University of Technology, faculty of Civil Engineering. 